\title{
Genotyping of Chlamydophila psittaci using a new DNA microarray assay based on sequence analysis of ompA genes Konrad Sachse*1, Karine Laroucau ${ }^{2}$, Helmut Hotzel ${ }^{3}$, Evelyn Schubert ${ }^{1}$, Ralf Ehricht ${ }^{4}$ and Peter Slickers ${ }^{4}$
}

Address: ${ }^{1}$ Friedrich-Loeffler-Institut (Federal Research Institute for Animal Health), Insitute of Molecular Pathogenesis, Jena, Germany, ${ }^{2}$ AFSSA, Unité Zoonoses Bactériennes, Maisons-Alfort, France, ${ }^{3}$ Friedrich-Loeffler-Institut (Federal Research Institute for Animal Health), Insitute of Bacterial Infections and Zoonoses, Jena, Germany and ${ }^{4}$ Clondiag Chip Technologies, Jena, Germany

Email: Konrad Sachse* - konrad.sachse@fli.bund.de; Karine Laroucau - k.laroucau@AFSSA.FR; Helmut Hotzel - helmut.hotzel@fli.bund.de; Evelyn Schubert - evelyn.schubert@fli.bund.de; Ralf Ehricht - ralf@clondiag.com; Peter Slickers - piet@clondiag.com

* Corresponding author

Published: 17 April 2008

BMC Microbiology 2008, 8:63 doi:10.1/86/147|-2/80-8-63
Received: 2 October 2007

Accepted: 17 April 2008

This article is available from: http://www.biomedcentral.com/I47I-2I80/8/63

(c) 2008 Sachse et al; licensee BioMed Central Ltd.

This is an Open Access article distributed under the terms of the Creative Commons Attribution License (http://creativecommons.org/licenses/by/2.0), which permits unrestricted use, distribution, and reproduction in any medium, provided the original work is properly cited.

\begin{abstract}
Background: The currently used genotyping system for the avian zoonotic pathogen Chlamydophila (C.) psittaci has evolved from serology and is based on ompA sequence variations. It includes seven avian and two non-avian genotypes. Restriction enzyme cleavage of the amplified ompA gene and, less frequently, ompA sequencing are being used for examination, but, beside methodological limitations, an increasing number of recently tested strains could not be assigned to any established genotype.
\end{abstract}

Results: Comprehensive analysis of all available ompA gene sequences has revealed a remarkable genetic diversity within the species $C$. psittaci, which is only partially covered by the present genotyping scheme. We suggest adjustments and extensions to the present scheme, which include the introduction of subgroups to the more heterogeneous genotypes $A, E / B$ and $D$, as well as six provisional genotypes representing so far untypable strains. The findings of sequence analysis have been incorporated in the design of a new DNA microarray. The ArrayTube ${ }^{\mathrm{TM}}$ microarray-based ompA genotyping assay has been shown to discriminate among established genotypes and identify so far untyped strains. Its high specificity, which allows detection of single-nucleotide polymorphisms, is due to the parallel approach consisting in the use of 35 hybridization probes derived from variable domains 2 and 4 of the ompA gene.

Conclusion: The traditional genotyping system does not adequately reflect the extent of intraspecies heterogeneity in ompA sequences of $C$. psittaci. The newly developed DNA microarraybased assay represents a promising diagnostic tool for tracing epidemiological chains, exploring the dissemination of genotypes and identifying non-typical representatives of $C$. psittaci.

\section{Background}

The obligate intracellular bacterium Chlamydophila (C.) psittaci, the causative agent of psittacosis in birds and humans, is a well-established pathogen responsible for regular outbreaks of disease in psittacine birds and domestic poultry [1], as well as cases of atypical pneumonia in exposed persons $[2,3]$. 
The current definition of the species C. psittaci includes the former avian serovars of Chlamydia psittaci, but even under the recently revised taxonomic classification of the family Chlamydiaceae [4] it remains a heterogeneous taxon in terms of host range and virulence. To facilitate epidemiological studies, strains of the agent were subdivided into serovars $\mathrm{A}, \mathrm{B}, \mathrm{C}, \mathrm{D}, \mathrm{E}$, and $\mathrm{F}$ on the basis of their immune reaction with a panel of monoclonal antibodies (MAbs) recognising specific epitopes of the major outer membrane protein (MOMP). Each serovar was assumed to exhibit more or less stringent host specificity [5-7]. Later on, Sayada et al. [8] suggested restriction fragment length polymorphism (RFLP), i.e. PCR amplification of the ompA gene with subsequent restriction enzyme analysis, for differentiation among C. psittaci isolates. Vanrompay et al. [9] were able to demonstrate by comparison of serotyping and PCR-RFLP that the serovars had genetic equivalents in the corresponding genotypes, which were defined by their restriction enzyme cleavage pattern. Thus, nine different genotypes have been generally accepted to date, seven of which are thought to predominantly occur in a particular order or class of Aves and two in non-avian hosts, i.e. genotype A in psittacine birds, $\mathrm{B}$ in pigeons, $\mathrm{C}$ in ducks and geese, $\mathrm{D}$ in turkeys, $\mathrm{E}$ in pigeons, ducks and others, $\mathrm{F}$ in parakeets, WC in cattle, and M56 in rodents. In addition, Geens et al. [10] suggested the introduction of genotype E/B to represent a group of isolates from ducks. Most of the avian genotypes have also been identified sporadically in isolates from cases of zoonotic transmission to humans.

While serotyping can be conducted with cultured strains only, PCR-RFLP was also used with DNA extracted from clinical samples [9]. However, there are obvious limitations as substantial amounts of a PCR amplicon are needed to produce distinctive and reproducible RFLP patterns on ethidium bromide-stained agarose gels. Related genotypes tend to have quite similar patterns, which may be difficult to distinguish, and typing results based on different enzyme patterns (e.g. AluI vs. MboII) may be contradictory. Genetically aberrant strains cannot be genotyped using the above-mentioned PCR-RFLP procedure. Sequencing of the ompA gene and alignment with type strain sequences can also be used to identify the genotype of $C$. psittaci strains [10,11], since genotype-specific sites are located in the gene's variable domains (VD) VD2 and VD4. However, all these approaches have been used in a rather pragmatic manner, i.e. with the aim of working out distinctive features of isolates for epidemiological purposes, while disregarding the scope of natural sequence variability and avoiding a molecular definition of individual genotypes at the nucleotide level.

In this situation, DNA microarray technology can be expected to provide added value because of its highly par- allel approach, which implies the potential to exploit minor sequence differences at multiple sites for discrimination among samples [12]. Using the ArrayTube ${ }^{\mathrm{TM}}(\mathrm{AT})$ platform, we recently demonstrated that the performance parameters of an AT microarray assay for species identification of chlamydiae were comparable to real-time PCR in terms of sensitivity and superior in specificity [13]. This prompted us to take further advantage of the AT technology's high discriminatory capacity $[14,12]$, rapidity and relatively low cost by exploring its suitability for ompA genotyping analysis. However, we immediately realized that a comprehensive analysis of currently known ompA sequences was necessary before considering the definition of specific probes for each genotype.

In the present study, we report the results of an extensive investigation on sequence similarity among all available ompA sequences from species of the genus Chlamydophila and describe the development of a DNA microarray-based assay for ompA genotyping of C. psittaci.

\section{Results}

\section{Analysis of ompA sequences of Chlamydophila strains}

The NCBI database was searched for ompA sequences by repeatedly running BLAST queries with sequences from already known entries. In the course of this process it became evident that some $C$. psittaci sequences were more similar to ompA of other Chlamydophila spp. than to any genotype of $C$. psittaci, which is in line with earlier publications [15-17]. Therefore, we extended our analysis to include all sequences from the genus Chlamydophila.

Comparison of all available GenBank entries revealed 63 unique sequences of ompA genes. The alignment of these sequences was the basis for calculation of a sequence similarity matrix (see Additional file 1) and construction of a split network graph (Fig. 1). These graphs are useful tools for presentation of sequence similarity-based relatedness, but are not designed to characterize phylogenetic relationships. We minimized distorting effects due to alignment of differently sized sequences by excluding the shortest items and selecting a 992-nt sequence window which contains all variable domains. The most striking feature of the split network graph is the great diversity among ompA variants of $C$. psittaci, which clearly exceeds variations among other species of the genus. While C. pneumoniae, C. abortus, C. pecorum, C. felis, and C. caviae each are located on a single branch, several genotypes of $C$. psittaci form their own separate branches. At least 12 distinct clades belonging to this species can be identified, of which only 5 can be directly attributed to currently accepted genotypes, i.e. $\mathrm{C}, \mathrm{D}, \mathrm{F}, \mathrm{M} 56$, and WC. Another remarkable feature is the $\mathrm{ABE}$ cluster, i.e. a grouping harboring the closely related genotypes A, B, E, and E/B. Similarity of the underlying ompA sequences is above $98 \%$ within the cluster and 


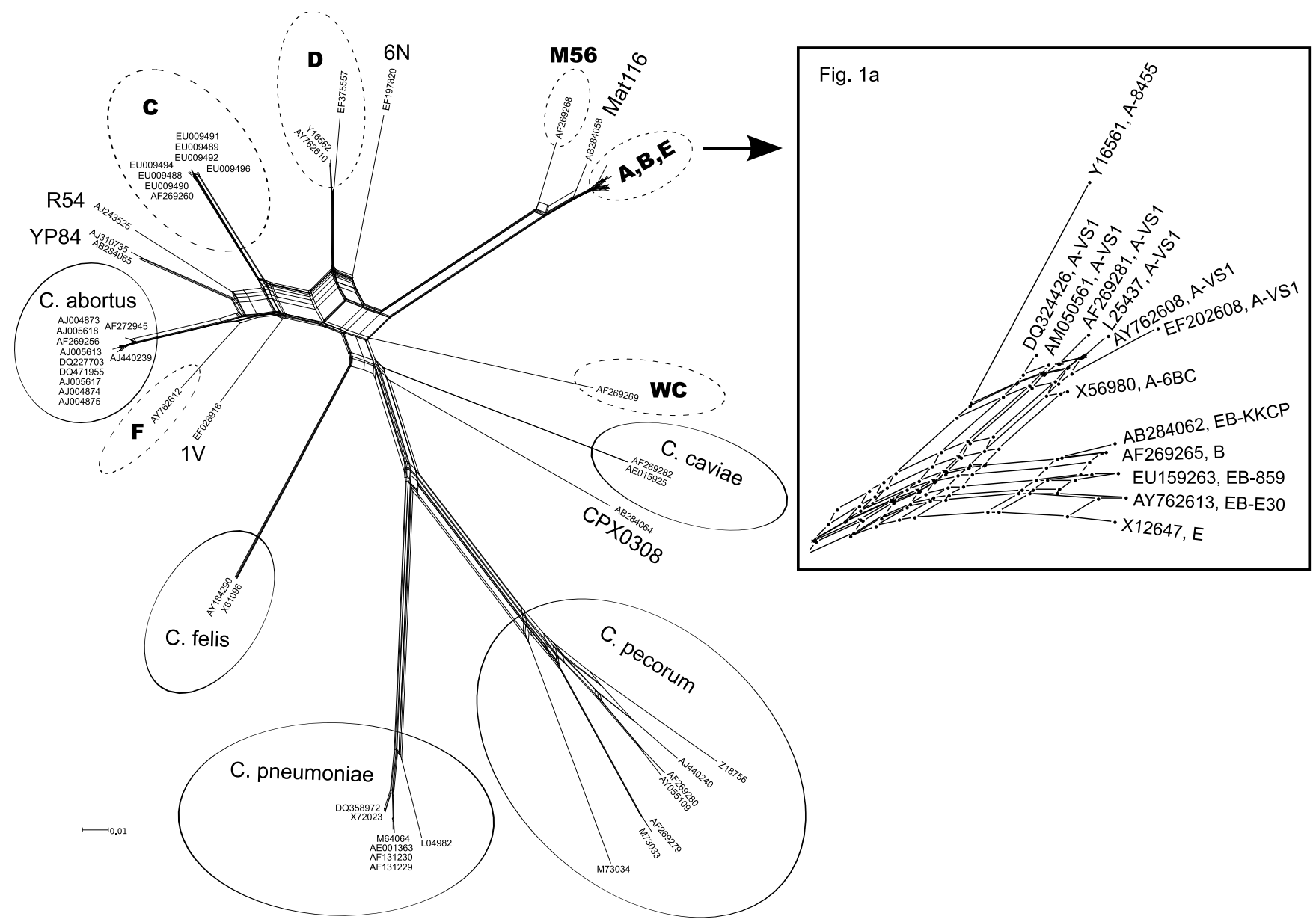

\section{Figure I}

Split network graph constructed from a global alignment of 63 ompA sequences retrieved from GenBank. Accession numbers are shown for each sequence represented. The length of connecting lines between two items is equivalent to their genetic distance. The scale bar denotes I substitution per 100 nucleotides. Clades representing an established genotype of $C$. psittaci are encircled by a dashed line and designated accordingly in bold print. Provisional genotypes are designated as suggested in Table I. Clades representing other Chlamydophila spp. are encircled by a solid line and labeled with the species name. Basic data of the strains represented by accession numbers can be found in Additional file 3 . Fig. Ia Detail showing the $A B E$ cluster. Subgroups of genotypes $A$ and $E / B$ are indicated at the respective GenBank accession number.

higher than $99.4 \%$ within the clade of genotypes B, E and $\mathrm{E} / \mathrm{B}$. To visualize these relationships, a magnified scale was used for presentation in Fig. 1a.

The M56 and Mat116 sequences represent less closely related side branches of the $\mathrm{ABE}$ stembranch. Strains of genotypes $\mathrm{C}, \mathrm{D}$ and $\mathrm{F}$ are all located clearly separated from each other, and a number of strains not assigned to one of the accepted genotypes (strains $1 \mathrm{~V}$, YP84, R54, 6N, and CPX0308) are placed fairly isolated, forming their own branches at considerable genetic distances from the established genotypes. Genotype F (represented by strain VS225), as well as strains YP84 and R54, were found to be side branches of the C. abortus branch.
As a result of this sequence analysis, we identified 20 individual type strains, each of which represents a unique ompA sequence. The findings are summarized in Table 1. In this classification, genotypes $\mathrm{A}, \mathrm{D}$ and $\mathrm{E} / \mathrm{B}$ can be further divided into subgroups, and the six strains at the bottom of the table represent untyped C. psittaci strains.

All in all, the present sequence analysis has shown that the extent of intra-species variation goes beyond the area covered by currently accepted genotypes.

\section{Selection of hybridization probes}

Using the global alignment of ompA sequences (see Additional file 2), we selected a panel of 35 oligonucleotide 
Table I: Identification of Chlamydophila psittaci genotypes and subgroups based on analysis of published ompA sequences

\begin{tabular}{|c|c|c|}
\hline Genotype-Subgroup & Type strain & GenBank acc. no. \\
\hline A-VSI & VSI, MN Zhang & AF269281.1 \\
\hline$A-6 B C$ & $6 \mathrm{BC}$ & $\underline{\times 56980.1}$ \\
\hline A-8455 & $84-55$ & Y16561.I \\
\hline B & $\mathrm{CP3}$ & AF269265.1 \\
\hline C & GR9, avian type C & $\underline{\mathrm{L} 25436.1}$ \\
\hline D-NJI & $\mathrm{NJI}$ & AF269266.1 \\
\hline$D-9 N$ & $9 \mathrm{~N}$ & EF375557.1 \\
\hline E & CPMN, EAE A22/M & $\underline{X} 12647.1$ \\
\hline EB-E30 & WS/RT/E30 & AY762613.1 \\
\hline EB-859 & $06-859 / 1$ & EUI59263.I \\
\hline EB-KКСР & KKCP-I & AB284062.1 \\
\hline $\mathrm{F}$ & VS225 & AF269259.1 \\
\hline M56 & M56 & AF269268.1 \\
\hline WC & WC & AF269269.1 \\
\hline $\mathrm{IV}^{*}$ & IV & EF028916.1 \\
\hline $6 N^{*}$ & $6 \mathrm{~N}$ & EFI97820.1 \\
\hline Matl I6* & Matl I6 & AB284058.I \\
\hline R54* & R54 & A) 243525.1 \\
\hline YP84* & Daruma-198I & AB284065.I \\
\hline CPX0308* & CPX0308 & $A B 284064.1$ \\
\hline
\end{tabular}

* provisional genotypes

probes for identification of $C$. psittaci genotypes, which are shown in Table 2. The probe binding sites are located in VD2 and VD4 of the ompA gene. A compilation showing the number of mismatches between targets of genotypes and hybridization probes is given in Table 3 . These data can be used for two purposes: a) to identify the genotype of the target DNA, and b) to predict signal intensities because perfect matches between probe and target will produce the strongest signals.

\section{Optimization of microarray hybridization}

To ensure the availability of sufficient amounts of target DNA for hybridization against a set of covalently bound oligonucleotide probes in a spatially accessible structure, amplification was conducted as duplex PCR. Using primer pairs VD1-f/VD2-r and 201CHOMP/ompA-rev, two biotinylated fragments containing VDs $1+2$ and VDs $3+4$, respectively, were produced. The resulting amplification products gave rise to hybridization signals at comparable intensity levels for VD2 and VD4 probes. In contrast, when PCR products comprising the entire ompA gene were hybridized, signals generated by binding to VD4 probes were significantly lower than those of VD2 probes (data not shown). This bias was compensated by doubling molar concentrations of the second primer pair in the above duplex PCR. Biotin labeling of target DNA via the use of 5'-biotinylated primers was preferred over internal labeling using biotin-dUTP because of higher sensitivity (data not shown) and lower cost.
To optimize the specificity of microarray hybridization, we systematically studied the influence of hybridization temperature $\left(\mathrm{T}_{\mathrm{H}}\right)$ and washing conditions. While hybridization patterns of the various genotypes were satisfactorily discernible at $\mathrm{T}_{\mathrm{H}}=60^{\circ} \mathrm{C}$, stringency was insufficient as indicated by poor resolution between signals of perfectmatch probes and one-mismatch probes (data not shown). In contrast, the introduction of high-temperature $\left(50^{\circ} \mathrm{C}\right)$ and low-salt buffer wash steps after both the hybridization reaction and incubation with the streptavidin-HRP conjugate led to high signal ratios of perfectmatch vs. one-mismatch probes, so that single-nucleotide polymorphisms (SNPs) could be detected (see next paragraph). This high-stringency wash protocol even allowed $\mathrm{T}_{\mathrm{H}}$ to be lowered to $50^{\circ} \mathrm{C}$ in order to gain sensitivity.

\section{Microarray hybridization of type strains}

Type strains of C. psittaci genotypes A, B, C, D, E, E/B, F, M56 and WC were examined using the AT ompA genotyping array. Barplots showing the distinct hybridization patterns are presented in Fig. 2. Comparison with theoretically expected, i.e. calculated patterns, revealed excellent agreement (data not shown) in all individual cases. Notably, regarding type strain patterns in the light of matching parameters given in Table 3, it could be confirmed that signal intensities of completely matching probes were significantly higher than those pertaining to probes having one or two mismatches to the target. For instance, Fig. 3 (upper part) illustrates that the signal of genotype B-specific probe VD2-03 with type B strain CP3 was more than 5 times stronger than with type $\mathrm{E}$ strain CPMN, which has a single mismatch in the target sequence. Conversely, the same applies to genotype E-specific probe VD2-04. Hybridization duplexes of targets and probes differing in two nucleotides were more than 10 times weaker than their perfect-match counterparts (see Fig. 3, lower part).

\section{Microarray hybridization of field isolates}

A group of 12 field strains of C. psittaci was examined using the present AT microarray (Table 4). Genotypes were identified from the pattern of hybridization signals according to the matching scheme in Table 3. In addition, all strains were ompA sequenced, and genotypes were determined according to individual positions in the above global alignment. PCR-RFLP results are also given for comparison in Table 4. The findings of AT ompA genotyping are in complete agreement with the data of the other two tests.

\section{Discussion}

The currently accepted system of genotyping for C. psittaci strains has evolved historically from its serological predecessor. The fact that serotypes have genotype equivalents [9], which has also been reported for, e.g., E. coli [14], 
Table 2: Sequence characteristics of the hybridization probes on the AT genotyping microarray

\begin{tabular}{|c|c|c|c|c|c|}
\hline Probe & Sequence* & Binding site* & Length & GC/\% & $\mathrm{Tm} /{ }^{\circ} \mathrm{C}$ \\
\hline VD2-0I & GGAATTGCTGGAAATAGCGAAAGTAATGC & AF269269.1 [466:494] & 29 & 41 & 60.9 \\
\hline VD2-02 & GGTTTTCAGCTGCAAGCTCAATCTC & M73035.I [554:578] & 25 & 48 & 60.3 \\
\hline VD2-03 & GGTTTTCAGCTACCAACTCAACCTCT & AF269265.I [488:5I3] & 26 & 46 & 60.3 \\
\hline VD2-04 & GGTTTTCAGCTACCAGCTCAACCT & AY327465.1 [488:5II] & 24 & 50 & 60.3 \\
\hline VD2-II & AGGAAACACCTTAACAAATGACCGACT & AJ310735.I [483:509] & 27 & 41 & 60.2 \\
\hline VD2-12 & GCTACCAACTCAACCTCTACCGATCT & AF269265.I [496:52I] & 26 & 50 & 61.0 \\
\hline VD2-13 & GAGCCTCTTTATCAGAGCAACTTCCA & A]243525.I [324:349] & 26 & 46 & 60.0 \\
\hline VD2-14 & AGCTCCTTAACAAATGACCAACTTCCC & AF269260.1 [478:504] & 27 & 44 & 60.7 \\
\hline VD2-15 & CCAGCTCAACCTCTACCGAGCT & AY327465.1 [500:521] & 22 & 59 & 61.0 \\
\hline VD2-2I & CCGTAGCAGCTGATCAACTTCCA & AF269259.I [482:504] & 23 & 52 & 60.1 \\
\hline VD2-22 & GCAGTTAGTACCGATCTTCCAAAGCA & AF269268.1 [505:530] & 26 & 46 & 60.5 \\
\hline VD2-23 & TCAATAATCAACTTCCAAACGTAGCCATCA & AF269266.I [494:523] & 30 & 37 & 60.6 \\
\hline VD2-24 & CTCTACCGAGCTTCCAATGCAACT & AY327465.1 [510:533] & 24 & 50 & 60.2 \\
\hline VD2-25 & СTCTACCGATCTTCCAACGCAACT & AF26928I.I [738:761] & 24 & 50 & 60.0 \\
\hline VD2-31 & CGATCTTCCAACGCAACTTCCTAAC & AF26928I.I [744:768] & 25 & 48 & 59.7 \\
\hline VD2-32 & CGATCTTCCAATGCAACTTCCTAACG & M73035.1 [582:607] & 26 & 46 & 59.9 \\
\hline VD2-33 & CGATCTTCCAAAGCAACTTCCTAACG & AF269268.I [5I6:54I] & 26 & 46 & 59.8 \\
\hline VD2-34 & CGAGCTTCCAATGCAACTTCCTAAC & AY327465.1 [516:540] & 25 & 48 & 59.9 \\
\hline VD4-0I & TGGCTACTGCTGTTTTAGACGCA & AF269269.1 [923:945] & 23 & 48 & 59.9 \\
\hline VD4-02 & TGGCCTCTGCTGTTATGAACTTGAC & AF269260.1 [9|4:938] & 25 & 48 & 60.5 \\
\hline VD4-03 & AGCCGCTGCTGTTTTGAACTTGA & AF269259.1 [915:937] & 23 & 48 & 61.2 \\
\hline VD4-II & CCCAAGCCTTATAGGATCAACCACTG & M73035.I [1047:1072] & 26 & 50 & 60.3 \\
\hline VD4-12 & CCAAGCCTTCTAGGATCAACCACTG & AF269265.I [982:1006] & 25 & 52 & 60.3 \\
\hline VD4-13 & CCAAGCCTTGTAGGATCAACCACTG & M73035.I [1048:1072] & 25 & 52 & 60.8 \\
\hline VD4-2I & CCTTATAGGATCAACCACTGCTTTGCC & M73035.I [1053:1079] & 27 & 48 & 61.1 \\
\hline VD4-22 & CCTTCTAGGATCAACCACTACTTTGCC & AF269262.I [927:953] & 27 & 48 & 60.4 \\
\hline VD4-23 & CCTTTTAGGGGAAGCCACAAATTTAGACT & A]243525.1 [799:827] & 29 & 41 & 60.7 \\
\hline VD4-24 & ССTTCTAGGATCAACCACTGCTTTGC & AF269265.I [987:1012] & 26 & 50 & 61.2 \\
\hline VD4-25 & AGGGCAAGCTACAAATTTAGATACTAGCA & A]310735.I [969:997] & 29 & 38 & 59.7 \\
\hline VD4-3I & ACTACTTTGCCCAATAATGGTGGTAAGG & AF269262.1 [943:970] & 28 & 43 & 60.4 \\
\hline VD4-32 & CTGCTTTGCCCAATAATAATAGTGGTAAGG & $\underline{Y 16561.1}$ [1004:1033] & 30 & 40 & 59.8 \\
\hline VD4-33 & TGCTTTGCCCAATAATAGTGGTAAGGA & M73035.I [107I:1097] & 27 & 41 & 59.8 \\
\hline VD4-34 & AGCTTTAGATGCTAGCAACAAATTCTGC & AF269259.1 [972:999] & 28 & 39 & 60.1 \\
\hline VD4-35 & GCTTTGCCCAATAATGCTGGTAAGG & AY327465.1 [1006:1030] & 25 & 48 & 60.2 \\
\hline VD4-36 & TGTCGACGGTACCAATACTTACTCTGA & AF269266.1 [981:1007] & 27 & 44 & 60.3 \\
\hline mean & & & 25 & 47 & 60.4 \\
\hline
\end{tabular}

*The exact binding position is referenced by the uniform sequence address (USA). This is the standard sequence notation scheme of the emboss software suite http://emboss.sourceforge.net/docs/.

proved to be helpful in the transition to the more accessible DNA-based typing methods, which are easier to standardize. However, given the serological history, it is not surprising that the ompA sequence analysis has revealed two notable limitations of the present genotype classification, i.e. the lack of complete coverage of naturally occurring strains and a general imbalance resulting from significant variations in genetic distances between individual genotypes. The latter reflects an inherent bias since the ideal panel would include genotypes genetically equidistant from each other.

Given the described deficiencies, the question about the usefulness of the present genotyping scheme inevitably arises. For instance, does the close genetic relatedness within the ABE cluster justify its subdivision into the four genotypes $\mathrm{A}, \mathrm{B}, \mathrm{E}$ and $\mathrm{E} / \mathrm{B}$ ?

The authors are of the opinion that there are important arguments in favor of maintaining the present classification and nomenclature, provided it is amended by a few adjustments and extensions.

i) Despite the amazing genetic heterogeneity displayed by ompA sequence database entries, it seems that the vast majority of field strains belong to the ABE cluster. This is indicated by several published studies $[18,10,11,19]$, by the data presented in Table 4 and also the long-term experience of the authors' laboratories (data not shown). The 
Table 3: Matching parameters of genotypes and subgroups with probes used on the AT microarray (numbers represent mismatches)

\begin{tabular}{|c|c|c|c|c|c|c|c|c|c|c|c|c|c|c|c|c|c|c|c|c|c|c|c|c|c|c|c|c|c|c|c|c|c|c|c|}
\hline \multirow{2}{*}{$\begin{array}{l}\begin{array}{l}\text { Probe } \\
\text { category }\end{array} \\
\text { Probe }\end{array}$} & \multicolumn{3}{|c|}{ ABE:VD2-a } & \multicolumn{2}{|c|}{ ABE:VD2-b } & \multicolumn{2}{|c|}{ ABE:VD2-c } & \multicolumn{4}{|c|}{ ABE:VD2-d } & \multicolumn{3}{|c|}{ ABE:VD4-b } & \multicolumn{3}{|c|}{ ABE:VD4-c } & \multicolumn{4}{|c|}{ ABE:VD4-d } & \multicolumn{3}{|c|}{ CDFRY:VD2-b } & \multicolumn{2}{|c|}{$\begin{array}{l}\text { CDFRY:VD } \\
2 c\end{array}$} & \multicolumn{2}{|c|}{$\begin{array}{l}\text { CDFRY:VD } \\
4-c\end{array}$} & \multicolumn{2}{|c|}{$\begin{array}{l}\text { CDRFY:VD } \\
4-d\end{array}$} & \multicolumn{2}{|l|}{$\begin{array}{l}\text { CF:V } \\
\text { D4-a }\end{array}$} & \multirow{2}{*}{$\begin{array}{l}\begin{array}{l}\text { M56:V } \\
\text { D2-c }\end{array} \\
\begin{array}{l}\text { VD2- } \\
22\end{array}\end{array}$} & \multirow{2}{*}{$\begin{array}{l}\text { WC:V } \\
\text { D2-a } \\
\begin{array}{l}\text { VD2- } \\
01\end{array}\end{array}$} & \multirow{2}{*}{$\begin{array}{l}\text { WC:V } \\
\text { D4-a } \\
\text { VD4- } \\
01\end{array}$} \\
\hline & $\begin{array}{l}\text { VD2 } \\
-02\end{array}$ & $\begin{array}{l}\text { VD2 } \\
-03\end{array}$ & $\begin{array}{l}\text { VD2 } \\
-04\end{array}$ & $\begin{array}{l}\text { VD2 } \\
-12\end{array}$ & $\begin{array}{l}\text { VD2 } \\
-15\end{array}$ & $\begin{array}{l}\text { VD2 } \\
-24\end{array}$ & $\begin{array}{l}\text { VD2 } \\
-25\end{array}$ & $\begin{array}{l}\text { VD2 } \\
-31\end{array}$ & $\begin{array}{l}\text { VD2 } \\
-32\end{array}$ & $\begin{array}{l}\text { VD2 } \\
-33\end{array}$ & $\begin{array}{l}\text { VD2 } \\
-34\end{array}$ & $\begin{array}{l}\text { VD4 } \\
-11\end{array}$ & $\begin{array}{l}\text { VD4 } \\
-12\end{array}$ & $\begin{array}{l}\text { VD4 } \\
-13\end{array}$ & $\begin{array}{l}\text { VD4 } \\
-21\end{array}$ & $\begin{array}{l}\text { VD4 } \\
-22\end{array}$ & $\begin{array}{l}\text { VD4 } \\
-24\end{array}$ & $\begin{array}{l}\text { VD4 } \\
-31\end{array}$ & $\begin{array}{l}\text { VD4 } \\
-32\end{array}$ & $\begin{array}{l}\text { VD4 } \\
-33\end{array}$ & $\underset{-35}{\text { VD4 }}$ & $\begin{array}{l}\text { VD2 } \\
-11\end{array}$ & $\begin{array}{l}\text { VD2 } \\
-13\end{array}$ & $\begin{array}{l}\text { VD2 } \\
-14\end{array}$ & $\begin{array}{l}\text { VD2 } \\
-21\end{array}$ & $\begin{array}{l}\text { VD2 } \\
-23\end{array}$ & $\begin{array}{l}\text { VD4 } \\
-23\end{array}$ & $\begin{array}{l}\text { VD4 } \\
-25\end{array}$ & $\begin{array}{l}\text { VD4 } \\
-34\end{array}$ & $\begin{array}{l}\text { VD4 } \\
-36\end{array}$ & $\begin{array}{l}\text { VD } 4 \\
-02\end{array}$ & $\begin{array}{l}\text { VD } \\
4-03\end{array}$ & & & \\
\hline \multicolumn{36}{|l|}{ Type } \\
\hline A-VSI & $0 ; 1$ & & & & & $2 ; 3$ & $0 ; 1$ & $0 ; 1$ & $1 ; 2$ & $1 ; 2$ & & 0 & 1 & 1 & 0 & 2 & 1 & & 3 & 0 & 2 & & & & & & & & & & & & & & \\
\hline A-6BC & 0 & & & & & 1 & 1 & 1 & 0 & 1 & & 0 & I & i & 0 & 2 & i & & 3 & 0 & 2 & & & & & & & & & & & & & & \\
\hline A-8455 & 0 & & & & & 2 & 0 & 0 & I & i & & 0 & i & i & 0 & 2 & i & & 0 & 3 & & & & & & & & & & & & & & & \\
\hline B & & 0 & 1 & 0 & & $i$ & 1 & I & 0 & i & & I & 0 & i & I & I & 0 & & 3 & 0 & 2 & & & & & & & & & & & & & & \\
\hline EB-E30 & & 1 & 0 & & 0 & 0 & 2 & & & & 0 & 1 & 0 & 1 & 1 & 1 & 0 & & & 2 & 0 & & & & & & & & & & & & & & \\
\hline EB-KKCP & & 0 & I & 1 & & 2 & 2 & 1 & 0 & 1 & & i & 0 & I & I & I & 0 & & 3 & 0 & 2 & & & & & & & & & & & & & & \\
\hline EB-859 & & I & 0 & 1 & 3 & 1 & 1 & 1 & 0 & 1 & & I & 0 & 1 & 1 & 1 & 0 & & & 2 & 0 & & & & & & & & & & & & & & \\
\hline E & & I & 0 & & 0 & 0 & 2 & & & & 0 & 2 & 1 & 2 & 2 & 0 & 1 & 0 & & 3 & 2 & & & & & & & & & & & & & & \\
\hline c & & & & & & & & & & & & & & & & & & & & & & & & $0 ; 2$ & & & & & & & 0 & & & & \\
\hline D-NJI & & & & & & & & & & & & & & & & & & & & & & & & & & 0 & & & & 0 & & & & & \\
\hline D-9N & & & & & & & & & & & & & & & & & & & & & & & & & & 4 & & & & & & & & & \\
\hline $\mathrm{F}$ & & & & & & & & & & & & & & & & & & & & & & & & & 0 & & & & 0 & & & 0 & & & \\
\hline R54 & & & & & & & & & & & & & & & & & & & & & & & 0 & & & & 0 & & & & & & & & \\
\hline YP84 & & & & & & & & & & & & & & & & & & & & & & 0 & & & & & & 0 & & & & & & & \\
\hline Matl 16 & & 2 & 2 & 2 & & 2 & 0 & 0 & 1 & 1 & & 0 & 1 & 1 & 0 & 2 & 1 & & & 1 & 1 & & & & & & & & & & & & & & \\
\hline M56 & & & & & & & & 1 & 1 & 0 & & 0 & 1 & 1 & 0 & 2 & 1 & & 3 & 0 & 2 & & & & & & & & & & & & 0 & & \\
\hline Wc & & & & & & & & & & & & & & & & & & & & & & & & & & & & & & & & & & 0 & 0 \\
\hline IV & & & & & 13 & & & & & & & & & & & & & & & & & & & & & & & & & & & & & & \\
\hline $6 \mathrm{~N}$ & & & & & & & & & & & & & & & & & & & & & & & & & & 2 & & & & & & & & & \\
\hline
\end{tabular}




\section{Hybridization patterns of $\mathrm{Cp}$. psittaci genotypes}
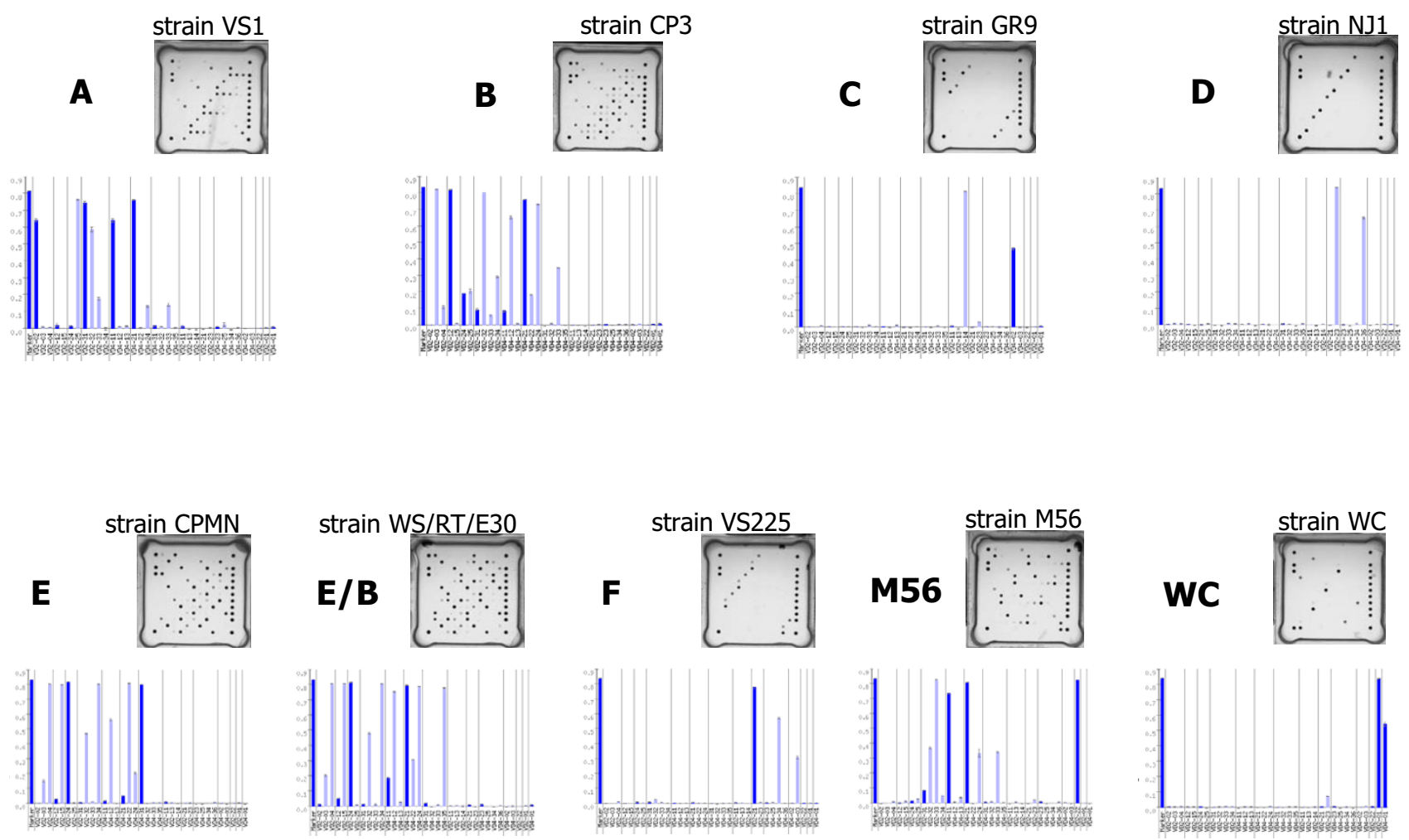

Figure 2

Hybridization patterns presented as microarray images and barplot diagrams of nine strains representing $C$. psittaci genotypes A, B, C, D, E, E/B, and F, as well as strains M56 and WC. The leftmost bar in each plot represents the signal of the internal staining control (biotinylated oligonucleotide probe).

small group of so far untyped isolates appears to represent only a small proportion of naturally occurring strains.

ii) Each genotype should be defined by a representative reference strain and its complete ompA sequence. While a genotyping system based on a single gene may not appear sufficiently comprehensive in the age of genomics, it should be noted that ompA encodes the major protein antigen of chlamydiae, and even the minor sequence variations including SNPs are mostly translated into different amino acids (and, potentially, different epitopes). The fact that genotype-specific antigens can be distinguished by specific MAbs indicates that these differences do matter in the context of immunogenicity, host preference, virulence and, thus, epidemiological importance. This is why we suggest maintaining the currently accepted genotypes, including the closely related ones of the ABE cluster. iii) To account for the natural variability of ompA sequences in $C$. psittaci strains, emerging branches of untyped isolates should become provisional genotypes until their epidemiological relevance and representative status are proven. To account for intra-genotype variability, we suggest that heterogeneous genotypes, such as A, E/ $B$ and $D$, should be further divided into subgroups named after a typical representative, e.g. A-VS1, A-6BC, etc. (see Table 1). This approach will ensure openness and flexibility of the genotyping scheme.

iv) The amended genotyping scheme should be re-evaluated and overhauled when a sufficiently large number of complete genome sequences of $C$. psittaci strains becomes available.

If ompA genotyping of C. psittaci is to be conducted in the framework of surveillance and monitoring studies, the performance of PCR-RFLP will be insufficient because of 


\section{Genotype B vs E}

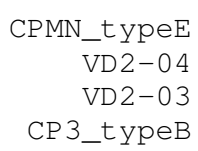

(481) TTAATAGGGTTTTCAGCTACCAGCTCAACCTCTACCGAGCTT

(1) ------GGTTTTCAGCTACCAGCTCAACCT---------

(1) -------GGTTTTCAGCTACCAACTCAACCTCT--------

(481) TTAATAGgGTTTTCAGCTACCAACTCAACCTCTACCGATCTT
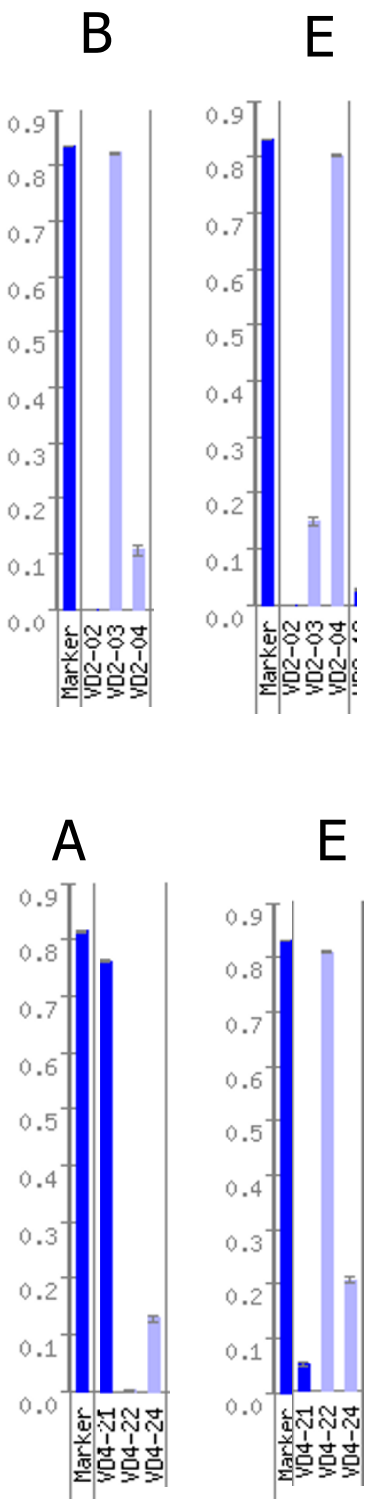

\section{Genotype A vs E}

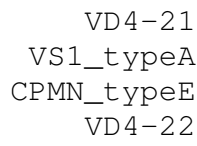

(1)

(961) TGGAACCCAAGCCTTATAGGATCAACCACTGCTTTGCCCAATAAT

(961) TGGAACCCAAGCCTTCTAGGATCAACCACTACTTTGCCCAATAAT

(1) -CCTTCTAGGATCAACCACTACTTTGCC-

\section{Figure 3}

Illustration of the specificity of the hybridization reaction on the AT microarray for genotyping of C. psittaci. Alignments of target (ompA gene segments) and probe sequences are shown on the left-hand side, and the respective hybridization signals (including internal staining marker) are given on the right-hand side. Upper part: The signal generated by duplex formation at genotype E-specific probe VD2-04 is reduced to approx. $20 \%$ when the target has a single mismatch, such as genotype B. This applies also to genotype B-specific probe VD2-03, when reacting with genotype E. Lower part: Signal is reduced to less than $10 \%$ in the case of two mismatches on the target sequence.

its limited sensitivity and inability to characterize atypical strains. As mentioned above, serological typing is limited to only six serotypes, but is not amenable to highthroughput examination and it lacks a strictly molecular basis. The real-time PCR procedure proposed by Geens et al (2005) can be very sensitive and specific for identification of seven of the established genotypes, but it is rather laborious and expensive because each sample has to be examined in seven individual runs. Sequencing of the complete ompA gene should serve as the gold standard for genotyping of $C$. psittaci since the respective DNA sequence contains all details necessary for genotype identification and the data can be stored in public databases to be easily accessible to researchers and diagnosticians. 
Table 4: Genotyping of $C$. psittaci field strains using the AT microarray and comparison with PCR-RFLP and ompA sequencing

\begin{tabular}{|c|c|c|c|c|}
\hline \multirow[t]{2}{*}{ Strain ID } & \multirow[t]{2}{*}{ Origin } & \multicolumn{3}{|c|}{ Genotype identification by } \\
\hline & & PCR-RFLP & ompA sequencing & ArrayTube genotyping* \\
\hline $\mathrm{Cl} / 97$ & sheep, Germany, 1997 & $\mathrm{C}$ & C & $\mathrm{C}$ \\
\hline C5/98 & calf, Germany, 1998 & $A$ & A & $A-6 B C$ \\
\hline $\mathrm{Cl} / 9 / 98$ & sheep, Germany, 1998 & $A$ & $A$ & $A-6 B C$ \\
\hline DCI5 & cattle, Germany, 200I & $A$ & $A$ & $A-6 B C$ \\
\hline DC28 & amazon parrot, Germany, $200 \mathrm{I}$ & A & A & A-VSI \\
\hline DC29 & amazon parrot, Germany, 200I & $A$ & A & $A-6 B C$ \\
\hline DC32 & pigeon, Germany, 2001 & B & $B$ & B \\
\hline Cal-10 & ferret, USA, 1936 & $\mathrm{E}$ & $E$ & $\mathrm{E}$ \\
\hline St04 & chicken, Germany, 2005 & $A$ & $A$ & A-VSI \\
\hline St05 & duck, Germany, 2005 & $E$ & $E / B$ & EB-E30 \\
\hline St06 & duck, Germany, 2005 & $A$ & $A$ & A-VSI \\
\hline St07 & duck, Germany, 2005 & $E$ & $E / B$ & EB-E30 \\
\hline
\end{tabular}

* AT hybridization signal pattern assigned according to Table 3

However, due to cost and labor intensiveness, it is not feasible at present to use DNA sequencing of this 1212-bp gene as a routine procedure in all diagnostic laboratories.

Being more rapid and economical, the AT microarray assay developed in the present study represents a powerful tool for sequence-based, sensitive and reproducible highthroughput genotyping. In principle, the procedure consists in parallel probing of 35 different targets and, in view of the recognition of minor nucleotide sequence variations including SNPs, amounts to re-sequencing the discriminatory regions in VDs 2 and 4 of the ompA gene. Future use of the AT ompA genotyping assay will enable diagnosticians in human and veterinary medicine to trace epidemiological chains, explore the dissemination of the various genotypes and other strains of $C$. psittaci, as well as identify new representatives of this amazing pathogen.

\section{Conclusion}

According to the data of ompA analysis, $C$. psittaci is genetically the most heterogeneous species of the genus Chlamydophila. The traditional genotyping system should be amended and extended because it does not adequately reflect the extent of intra-species heterogeneity. Serology, PCR-RFLP and real-time PCR are unable to discriminate among all currently accepted genotypes and identify strains of new types. While genotyping based on complete ompA sequences should serve as gold standard, many of the smaller laboratories may not be able to use it in routine diagnosis. The results of the present study have demonstrated that the newly developed DNA microarraybased $o m p$ A genotyping assay represents a promising diagnostic tool.

\section{Methods \\ Chlamydial strains}

Genomic DNA of the following reference strains, each representing a particular genotype, was used to generate master patterns for the ompA genotyping assay:

VS1 (genotype A, from parrot, USA, 1985), CP3 (genotype $\mathrm{B}$, from pigeon, USA, 1957), GR9 (genotype C, duck, Europe, year unknown), NJ1 (genotype D, from turkey, USA, 1959), CPMN (genotype $\mathrm{E}$, ferret/human, USA, 1934), VS225 (genotype F, parakeet, USA, 1991), all of which were described in reference 5 and obtained from the chlamydia strain collection of AFSSA, Maisons-Alfort, France. Strains WS/RT/E30 (genotype E/B; isolated from a duck, Germany, 2001, reference 10), WC (from cattle, USA, 1990, reference 7) and M56 (from muskrat, USA, 1961, reference 7) were kindly provided by Daisy Vanrompay, University of Ghent, Belgium.

In addition, the field isolates given in Table 4 were examined in this study.

\section{Sequencing of the ompA gene}

The complete gene was amplified by PCR using primers CTU (5'-ATG AAA AAA CTC TTG AAA TCG G-3') and ompA-rev (5'-TCC TTA GAA TCT GAA TTG AGC-3') using the following cycling profile: initial denaturation $96^{\circ} \mathrm{C}$ for $60 \mathrm{sec}, 40$ cycles of $96^{\circ} \mathrm{C} / 15 \mathrm{sec}, 50^{\circ} \mathrm{C} / 60 \mathrm{sec}, 72^{\circ} \mathrm{C} /$ $60 \mathrm{sec}$, final extension $72^{\circ} \mathrm{C}$ for $60 \mathrm{sec}$.

Products were electrophoresed in $1 \%$ agarose gels, and the specific bands of approximately 1200 bp were excised with a scalpel and DNA extracted using the innuPREP Gel Extraction Kit (Analytik Jena, Jena, Germany). DNA sequencing was carried out by cycle sequencing using the BigDye $^{\mathrm{TM}}$ Terminator Cycle Sequencing Ready Reaction Kit 
(Applied Biosystems, Darmstadt, Germany) according to the instructions of the manufacturer. The following primers were used: CTU, VD1-f (5'-ACT ACG GAG ATT ATG TTT TCG ATC GTG T-3'), VD2-r (5'-CGT GCA CCY ACG CTC CAA GA-3'), CHLAGEN-1 (5'-CGG CTG CAT TCA ACT TGG-3'), 201CHOMP (5'-GGI GCW GMI TTC CAA TAY GCI CAR TC-3'), and ompA-rev. Nucleotide sequences were determined on an ABI Prism 310 Genetic Analyzer (Applied Biosystems).

\section{In silico analysis of ompA sequences}

All available sequences of the ompA gene of $C$. psittaci were downloaded for analysis from the database of the National Center for Biotechnology Information (NCBI). A total of 210 sequence entries were found (by the date of manuscript submission). Of these, 89 sequences shorter than $500 \mathrm{nt}$ were excluded from further analysis for failing to cover all four variable domains. Of the remaining 121 entries, 68 were found to belong to C. psittaci and 53 to other Chlamydophila species. Only 25 sequences from $C$. psittaci and 28 from other Chlamydophila spp. were found to include the full coding sequence (CDS) of approximately $1212 \mathrm{nt}$. In contrast, 70 entries lacked terminal parts of the CDS, but were retained because for some genotypes not a single complete sequence was available. All items were included in a global ompA sequence alignment using the program E-INS-I of the MAFFT package [20].

Classification was done first by visual inspection of the alignment using Clustal X [21] and subsequently by calculating a sequence similarity matrix (see Additional file 1), from which a split network graph was constructed (Fig. 1) using the program SplitsTree4 [22].

Before starting the similarity matrix calculation, redundant items were removed, i.e. any sequence that could be retrieved under another sequence was deleted, and only unique sequences were kept. The sequences were brought to identical length by cropping highly conserved 3' ends in order to avoid distorted results due to alignment of differently sized sequences. Thus, the analyzed segment comprised 992 nucleotide positions (median sequence length $942 \mathrm{nt}$ ) including all four variable domains. The final set contained 63 unique sequences.

\section{Microarray design}

The present array carries 35 oligonucleotide probes recognizing targets from VD2 and VD4 of the ompA gene of Cp. psittaci. Nucleotide sequences of all probes are provided in Table 2 . The oligonucleotides had the following features: average size $26 \mathrm{nt}(22-30)$, melting temperature $60.3^{\circ} \mathrm{C}$ (59.7 - 61.2), G+C contents 46.0 mol-\% (37.0 - 59.0). Each probe sequence was subjected to local BLAST analysis against all known C. psittaci ompA sequences to verify the respective genomic target and rule out unwanted cross-reactions. Biotinylated oligonucleotide probes were added to monitor the staining reaction, mark the corners of the array and facilitate normalization of signal intensities. Each genotype probe was spotted four-fold, the controls 15 -fold, thus bringing the total number of spots on the array to 155. Fabrication of the AT microarrays was described previously [12].

\section{DNA extraction}

Cell cultured strains were DNA extracted using the High Pure PCR Template Preparation Kit (Roche Diagnostics, Mannheim, Germany).

\section{Biotinylation PCR and AT hybridization}

Target DNA was amplified and biotinylated by duplex PCR using two pairs of ompA primers covering all variable domains. Primer pair VD1-f and VD2-r (sequence as above, but 5'-biotinylated) gives rise to a 418 -bp product which includes VD1 and VD2, whereas primers 201CHOMP and ompA-rev (sequence as above, but 5'biotinylated) defined a product of 570 bp covering VD3 and VD4. The temperature-time profile was: initial denaturation at $96^{\circ} \mathrm{C}$ for $60 \mathrm{sec}, 40$ cycles of $94^{\circ} \mathrm{C}$ for $30 \mathrm{sec}$, $50^{\circ} \mathrm{C}$ for $60 \mathrm{ssec}, 72^{\circ} \mathrm{C}$ for $30 \mathrm{sec}$, and final elongation at $72^{\circ} \mathrm{C}$ for $240 \mathrm{sec}$.

Each $20-\mu \mathrm{l}$ reaction contained $10 \mathrm{pmol}$ of the first and 20 pmol of the second primer pair, as well as $1 \mathrm{mM}$ each of dNTP mix, 1 U Taq DNA polymerase (Fermentas, St. Leon-Roth, Germany), $2 \mu \mathrm{l} 10 \times$ PCR buffer (Fermentas), $1 \mu \mathrm{l} 50 \mathrm{mM} \mathrm{MgCl}_{2}$, and $1 \mu \mathrm{l}$ of the DNA template.

The AT vessel was conditioned by washing with $500 \mu \mathrm{l}$ each of deionized water and Hybridization buffer 1 (Clondiag Chip Technologies, Jena, Germany) at $50^{\circ} \mathrm{C}$ for $5 \mathrm{~min}$. All incubations were carried out upon slight shaking (550 rpm) on a heatable horizontal tube shaker (Thermomixer comfort, Eppendorf, Cologne, Germany). For denaturation, $1 \mu \mathrm{l}$ of the 5'-biotinylated PCR product was diluted with $99 \mu$ l hybridization buffer in a separate tube, heated at $95^{\circ} \mathrm{C}$ for $5 \mathrm{~min}$ and put on ice. After transfer into the AT, hybridization was allowed to proceed at $50^{\circ} \mathrm{C}$ for $60 \mathrm{~min}$. The supernatant was then discarded, and the array was washed consecutively with $500 \mu \mathrm{l} 2 \times \mathrm{SSC} /$ $0.01 \%$ Triton X-100 $\left(50^{\circ} \mathrm{C}, 5 \mathrm{~min}\right), 500 \mu \mathrm{l} 2 \times \operatorname{SSC}\left(50^{\circ} \mathrm{C}\right.$, $5 \mathrm{~min}), 500 \mu \mathrm{l} 0.2 \times \mathrm{SSC}\left(50^{\circ} \mathrm{C}, 5 \mathrm{~min}\right)$, and $500 \mu \mathrm{l} 0.2 \times$ $\mathrm{SSC}\left(35^{\circ} \mathrm{C}, 5 \mathrm{~min}\right)$. Vacant binding sites of the microarray were blocked by incubation with a $2 \%$ solution of Blocking Reagent (Roche) in hybridization buffer at $30^{\circ} \mathrm{C}$ for $15 \mathrm{~min}$. Subsequently, the AT was incubated with $100 \mu \mathrm{l}$ of a 1:5000 dilution $(0.5 \mu \mathrm{g} / \mathrm{ml})$ of streptavidin-peroxidase polymer (Sigma-Aldrich, Taufkirchen, Germany) at $30^{\circ} \mathrm{C}$ for $15 \mathrm{~min}$ followed by three wash steps, i.e. $500 \mu \mathrm{l}$ $2 \times \mathrm{SSC} / 0.01 \%$ Triton $\mathrm{X}-100\left(30^{\circ} \mathrm{C}, 5 \mathrm{~min}\right), 500 \mu \mathrm{l} 2 \times$ $\operatorname{SSC}\left(20^{\circ} \mathrm{C}, 5 \mathrm{~min}\right), 500 \mu \mathrm{l} 0.2 \times \operatorname{SSC}\left(20^{\circ} \mathrm{C}, 5 \mathrm{~min}\right)$. 
Finally, $100 \mu \mathrm{l}$ of the peroxidase substrate Seramun Grün (Seramun Diagnostica, Heidesee, Germany) were added. Hybridization signals were measured using an ATR-01 transmission reader (Clondiag) and processed using the Iconoclust software, version 2.3 (Clondiag).

Normalized intensities of the spots were calculated according to the following equation:

$\mathrm{NI}=1-(\mathrm{M} / \mathrm{BG})$, with NI being the normalized intensity, $M$ the average intensity of the spot, and BG the intensity of the local background. Values range from 0 (no signal) to 1 (strong signal).

\section{PCR-RFLP genotyping}

Extracted DNA was amplified by PCR using primers CTU/ $\mathrm{CTL}$, and the product was subjected to restriction enzyme digestion using AluI and MboII as described by Sayada et al. [8]. Following agarose gel electrophoresis, cleavage patterns were compared with those of the reference strains for genotypes A, B, C, D, E and F.

\section{Availability and requirements}

National Center for Biotechnology Information (NCBI): http://www.ncbi.nlm.nih.gov/Genbank/

\section{Authors' contributions}

KS conceived of the study and coordinated it, participated in bioinformatic work, supervised laboratory work and drafted the manuscript. KL conducted PCR-RFLP testing and provided most of the reference strains and their DNA. $\mathrm{HH}$ conducted ompA sequencing and participated in the design of the study. ES conducted cell culture of the chlamydial strains used. RE participated in the design of the study, as well as in the sequence alignment and further analysis, and supervised part of the laboratory work. PS participated in designing the study and in bioinformatic work. All authors read and approved the final manuscript.

\section{Additional material}

\section{Additional file 1}

Sequence similarity matrix. Calculated similarity matrix of all unique $\mathrm{omp} A$ sequences of C. psittaci strains, on which the split network graph in Fig. 1 is based.

Click here for file

[http://www.biomedcentral.com/content/supplementary/14712180-8-63-S1.nex]

\section{Additional file 2}

Global alignment of ompA sequences found in the GenBank database. Alignment of 63 unique ompA sequences of $\mathrm{C}$. psittaci strains from the GenBank database (992 positions)

Click here for file

[http://www.biomedcentral.com/content/supplementary/1471-

2180-8-63-S2.fna]

\section{Additional file 3}

Basic data of C. psittaci strains included in Fig. 1 and the final ompA sequence alignment. Basic data of C. psittaci strains and GenBank accession numbers of ompA sequences included in the graph in Fig. 1 and the global ompA sequence alignment in Additional file 2

Click here for file

[http://www.biomedcentral.com/content/supplementary/14712180-8-63-S3.xls]

\section{Acknowledgements}

We thank Daisy Vanrompay for providing three important type strains. The authors also wish to thank Christine Grajetzki, Elke Müller, Simone Bettermann, Sabine Scharf, Byrgit Hofmann and Karola Zmuda for excellent technical assistance. This study is an integral part of the European COST Action 855 "Animal Chlamydioses and the Zoonotic Implications".

\section{References}

I. Vanrompay D, Ducatelle R, Haesebrouck F: Chlamydia psittaci infections: a review with emphasis on avian chlamydiosis. Vet Microbiol 1995, 45:93-II9.

2. Moroney JM, Guevara R, Iverson C, Chen FM, Skelton SK: Detection of chlamydiosis in a shipment of pet birds, leading to recognition of an outbreak of clinically mild psittacosis in humans. Clinic Infect Dis 1998, 26: I 425-1429.

3. Essig A, Zucs P, Susa M, Wasenauer G, Mamat U, Hetzel M, Vogel U, Wieshammer S, Brade H, Marre R: Diagnosis of ornithosis by cell culture and polymerase chain reaction in a patient with chronic pneumonia. Clin Infect Dis 1995, 21:1495- 497.

4. Everett KD, Bush RM, Andersen AA: Emended description of the order Chlamydiales, proposal of Parachlamydiaceae fam. nov. and Simkaniaceae fam. nov., each containing one monotypic genus, revised taxonomy of the family Chlamydiaceae, including a new genus and five new species, and standards for the identification of organisms. Int J Syst Bacteriol 1999, 49(Pt 2):4I5-440.

5. Andersen AA: Serotyping of Chlamydia psittaci isolates using serovar-specific monoclonal antibodies with the microimmunofluorescence test. J Clin Microbiol I99I, 29:707-7II.

6. Vanrompay D, Andersen AA, Ducatelle R, Haesebrouck F: Serotyping of European isolates of Chlamydia psittaci from poultry and other birds. J Clin Microbiol 1993, 3 I: I34-137.

7. Andersen AA: Two new serovars of Chlamydia psittaci from North American birds. J Vet Diagn Invest 1997, 9:159-164.

8. Sayada C, Andersen AA, Storey C, Milon A, Eb F, Hashimoto N, Hirai $\mathrm{K}$, Elion J, Denamur $\mathrm{E}$ : Usefulness of ompI restriction mapping for avian Chlamydia psittaci isolate differentiation. Res Microbiol 1995, I46:155-165.

9. Vanrompay D, Butaye P, Sayada C, Ducatelle R, Haesebrouck F: Characterization of avian Chlamydia psittaci strains using omp I restriction mapping and serovar-specific monoclonal antibodies. Res Microbiol 1997, I 48:327-333.

10. Geens T, Desplanques A, Van Loock M, Bonner BM, Kaleta EF, Magnino S, Andersen AA, Everett KD, Vanrompay D: Sequencing of the Chlamydophila psittaci ompA gene reveals a new genotype, $E / B$, and the need for a rapid discriminatory genotyping method. J Clin Microbiol 2005, 43:2456-246I.

II. Heddema ER, van Hannen EJ, Duim B, Vandenbroucke-Grauls CM, Pannekoek Y: Genotyping of Chlamydophila psittaci in human samples. Emerg Infect Dis 2006, I 2:1989-1990. 
12. Sachse $K$, Hotzel H, Slickers P, Ellinger T, Ehricht R: DNA microarray-based detection and identification of Chlamydia and Chlamydophila spp. Mol Cell Probes 2005, 19:4I-50.

13. Borel N, Kempf E, Hotzel H, Schubert E, Torgerson P, Slickers P, Ehricht R, Tasara T, Pospischil A, Sachse K: Direct identification of chlamydiae from clinical samples using a DNA microarray assay - a validation study. Mol Cell Probes 2008, 22:55-64.

14. Ballmer K, Korczak BM, Kuhnert P, Slickers P, Ehricht R, Hachler H: Fast DNA serotyping of Escherichia coli by use of an oligonucleotide microarray. J Clin Microbiol 2007, 45:370-379.

15. Fukushi H, Hirai K: Immunochemical diversity of the major outer membrane protein of avian and mammalian Chlamydia psittaci. J Clin Microbiol 1988, 26:675-680.

16. Herrmann B, Pattersson B, Everett KDE, Mikkelsen NE, Kirsebom LA: Characterization of the rnp $B$ gene and RNase P RNA in the order Chlamydiales. Int J Syst Evol Microbiol 2000, 50: I 49-I 58.

17. Van Loock M, Vanrompay D, Herrmann B, van der Stappen J, Volckaert G, Goddeeris BM, Everett KD: Missing links in the divergence of Chlamydophila abortus from Chlamydophila psittaci. Int J Syst Evol Microbiol 2003, 53:76I-770.

18. Geens T, Dewitte A, Boon N, Vanrompay D: Development of a Chlamydophila psittaci species-specific and genotype-specific real-time PCR. Vet Res 2005, 36:787-797.

19. Vanrompay D, Harkinezhad T, van de Walle M, Beeckman D, van Droogenbroeck C, Verminnen K, Leten R, Martel A, Cauwerts K: Chlamydophila psittaci transmission from pet birds to humans. Emerg Infect Dis 2007, 13:1 108-1 II 10.

20. Katoh K, Kuma K, Miyata T, Toh H: Improvement in the accuracy of multiple sequence alignment program MAFFT. Genome Inform 2005, 16:22-33.

21. Thompson JD, Gibson T], Plewniak F, Jeanmougin F, Higgins DG: The ClustalX windows interface: flexible strategies for multiple sequence alignment aided by quality analysis tools. Nucleic Acids Res 1997, 24:4876-4882.

22. Huson DH, Bryant D: Application of phylogenetic networks in evolutionary studies. Mol Biol Evol 2006, 23:254-267.

\section{Publish with Bio Med Central and every scientist can read your work free of charge}

"BioMed Central will be the most significant development for disseminating the results of biomedical research in our lifetime. "

Sir Paul Nurse, Cancer Research UK

Your research papers will be:

- available free of charge to the entire biomedical community

- peer reviewed and published immediately upon acceptance

- cited in PubMed and archived on PubMed Central

- yours - you keep the copyright
BioMedcentral 